\title{
FINANCIAMENTO PRIVADO DE CAMPANHA ELEITORAL POR PESSOA JURÍDICA - VISÃO DEMÓCRÁTICA
}

\author{
Raimundo Augusto Fernandes Neto ${ }^{1}$ \\ Renata Albuquerque Lima ${ }^{2}$
}

\section{RESUMO}

Análise do financiamento privado de campanha por pessoas jurídicas em face da decisão do Supremo Tribunal Federal na ADI 4650/DF e sua influência no sistema normativo de financiamento de campanha no Brasil. Estuda os efeitos deletérios da referida vedação na participação política das associações organizadas e empresas privadas, já que, apesar de sofrerem consequências das politicas públicas, tiveram sua liberdade de expressão reduzida, em detrimento do pluralismo democrático. Para tanto, após contextualização histórica, foram avaliados os fundamentos jurídico-políticos da decisão do STF e a repercussão nas eleições municipais de 2016.

Palavras-chave: Democracia. Financiamento de Campanhas Eleitorais. Participação de pessoas jurídicas. Reforma Política. Constitucionalidade.

\section{PRIVATE FINANCING OF THE ELECTORAL CAMPAIGN BY A LEGAL PERSON- DEMOCRATIC VISION}

\begin{abstract}
Analysis of private campaign financing by legal entities in the face of the decision of the Federal Supreme Court in ADI 4650/DF and its influence on the normative system of campaign financing in Brazil. It studies the deleterious effects of this prohibition on the political participation of organized associations and private companies, since, although they suffer from public policy consequences, they have had their freedom of political expression reduced, to the detriment of democratic pluralism. For that purpose, after a historical context, the legal-political foundations of the STF decision and its repercussion in the municipal elections of 2016 were evaluated.
\end{abstract}

Keywords: Democracy - Financing of Electoral Campaigns - Participation of legal entities. Constitutionality.

\footnotetext{
${ }^{1}$ Bacharel em Direito pela Universidade Federal do Ceará; especialista em Processo Penal pela Universidade de Fortaleza; especialista em Direito e Processo Eleitoral pela Universidade de Fortaleza; especialista em Direito e Processo Administrativo pela Universidade de Fortaleza; mestrando em Direito e Desenvolvimento pelo Centro Universitário Christus - UNICRISTUS. Advogado militante em Direito Eleitoral. Email: fernandesnetoadv@ @otmail.com*

${ }^{2}$ Pós-Doutora em Direito pela Universidade Federal de Santa Catarina. Doutora em Direito Constitucional pela Universidade de Fortaleza - UNIFOR. Email: realbuquerque@yahoo.com*
} 


\section{INTRODUÇÃO}

A crise de representação política é um dos problemas mais latentes, hoje, da democracia, a qual se estende desde a participação, cada vez menor, do eleitor na eleição à sua completa desvinculação dos seus representantes eleitos.

O Supremo Tribunal Federal, no julgamento da ADI 4650/DF, em vez de incentivar a participação democrática, excluiu as pessoas jurídicas privadas de direito da livre expressão política, por meio de doações e financiamento de campanhas eleitorais e partidos políticos, sob os argumentos principiológicos de conflito com as regras eleitorais, que permitiam a doação política por parte de pessoas jurídicas privadas.

O ativismo político da Corte Suprema em muito supera os casos anteriores de ativismo político por ela analisados, protagonizando verdadeira reforma política, e, se não, um início dela, à revelia da participação democrática, para tanto, elegendo a pessoa jurídica privada como fonte das mazelas do sistema político.

Haverá, realmente, colisão dos princípios da democracia, da igualdade e republicano e o regramento legal proposto, especificamente, acerca da inclusão das pessoas jurídicas privadas como financiadoras da atividade política?

A resposta para o tal questionamento é o objeto deste ensaio.

\section{DESENVOLVIMENTO}

O financiamento de campanhas eleitorais é um dos temas mais intrigantes e discutidos no mundo ocidental democrático, reafirmando a máxima de Churchill ao asseverar que "A democracia é a pior forma de governo, salvo todas as demais formas que têm sido experimentadas de tempos em tempos" (CHURCHILL, 1947, online).

A relação da política com o capital sempre fragilizou o ideal democrático moderno de um governo representativo da maioria, com respeito aos direitos das minorias. O dinheiro é, ao mesmo tempo, necessário para a realização do ideal democrático e, na maioria das vezes, para seu desvirtuamento.

Atualmente, as campanhas eleitorais são altamente dispendiosas. Exigem dos candidatos, partidos e seus financiadores a aplicação de grandes valores. O custo com os 
comícios, propaganda impressa, empresas de marketing, elaboração de programas eleitorais em rádio, televisão, redes sociais, assessoria contábil, assessoria jurídica, de imprensa, de logísticas de deslocamento de candidatos e apoiadores transformaram as campanhas eleitorais em grandes estruturas.

Seguramente, aquele que melhor se expressa visualmente tem o melhor e mais elaborado programa eleitoral, bem como presença física em todos os lugares, visitando vários estados, cidades ou bairros, num só dia, é que dispõe das melhores assessorias e, por via de consequência, leva substancial vantagem em relação aos demais candidatos.

Por outro lado, apesar de não se fazer política sem dinheiro, a maneira de sua apresentação não deve substituir, em importância, seu conteúdo, o que tem como consequência a eleição de governos ilegítimos, o que é tratado no mundo ocidental como crise de representação.

Transformam a eleição num mundo de ficção, apenas como ato legitimador do poder constituído. Como leciona Luís Felipe Miguel (2014, p.54), sobre a teoria da democracia elitista, "Ao votar, o povo não decide nada, mas pensa que decide, e por isso, se dispõe a obedecer aos governantes."

No Brasil, a impressão que se tem é de que o problema é ainda mais agudo, quando se acorda, diariamente, com os noticiários que revelam a relação pouco republicana entre o interesse privado, os partidos políticos e os candidatos, alcançando somas impressionantes e trazendo a público novos conceitos, como a Caixa 1, a Caixa 2 e a Caixa 3, nas palavras do ministro Herman Benjamim (TSE - HERMAN BENJAMIN VOTA PELA CASSAÇÃO DA CHAPA DILMA-TEMER POR ABUSO DE PODER POLÍTICO E ECONÔMICO, 2017, online), expostas no julgamento da chapa Dilma/Temer no Tribunal Superior Eleitoral.

Longe de ser um caso isolado, os julgamentos das ações que visam à cassação da chapa vitoriosa nas eleições de 2014 revelam uma corrupção sistêmica na relação dos financiamentos de campanha com o privado.

O problema de fundo revelado é muito maior do que a criminalização dos caixas 2 e 3. Ele é centralizado na discussão do modelo de financiamento da política que os cidadãos brasileiros querem e necessitam, como medida de garantia do regime democrático, da legitimidade das eleições e representação. Se, exclusivamente, público ou privado, se privado, 
mediante doações de pessoas físicas ou jurídicas, ou misto, como tradicionalmente sempre foi no Brasil.

Em 2015, o Supremo Tribunal Federal se arvorou a intervir nesse tema eminentemente político, vedando o financiamento de partidos e campanhas eleitorais por pessoa jurídica, ao julgar procedente em parte a ADI n ${ }^{\circ} 4650 / \mathrm{DF}^{3}$, proposta pela Ordem dos Advogados do Brasil, alterando, significativamente, o modelo de financiamento de campanha, implantado desde 1993.

\title{
2.1 Breve histórico
}

A Constituição Federal de 1988 não estabeleceu regras de financiamento de campanhas eleitorais, remetendo sua definição para legislação infraconstitucional. Fux e Frazão (2016, p.71) explicam:

\begin{abstract}
A constituição de 1988 não contem, em qualquer de suas disposições constitucionais, um tratamento especifico e exaustivo no que concerne ao financiamento de campanhas eleitorais. Deveras, diversamente do elevado grau de detalhamento com que cuidou de inúmeros aspectos da vida, o constituinte originário não entregou ao legislador um modelo pré-elaborado de arrecadação de fundos para as campanhas eleitorais. Poderia fazê-lo, mas verdadeiramente, não o fez.
\end{abstract}

A primeira eleição direta para presidente, após o advento da Carta Política que vigora, foi feita ainda sob a vigência da Lei nº 5682/71 (Lei Orgânica dos Partidos Político - LOPP), ainda originária do regime civil-militar. A legislação, apesar de prever um sistema misto de financiamento de campanha eleitoral, não permitia a utilização de recursos de pessoa jurídica, quer pública ou privada, e dizia expressamente, em seu art. 91, inciso IV, que é vedado aos partidos políticos "receber, direta ou indiretamente, sob qualquer forma ou pretexto,

\footnotetext{
${ }^{3}$ TSE, Acórdão na ADI no 4650/DF. "Vistos, relatados e discutidos estes autos, acordam os Ministros do Supremo Tribunal Federal, em Sessão Plenária, sob a Presidência do Senhor Ministro Ricardo Lewandowski, na conformidade da ata de julgamento e das notas taquigráficas, por maioria e nos termos do voto do Ministro Relator, em julgar procedente em parte o pedido formulado na ação direta para declarar a inconstitucionalidade dos dispositivos legais que autorizavam as contribuições de pessoas jurídicas às campanhas eleitorais, vencidos, em menor extensão, os Ministros Teori Zavascki, Celso de Mello e Gilmar Mendes, que davam interpretação conforme, nos termos do voto ora reajustado do Ministro Teori Zavascki. O Tribunal rejeitou a modulação dos efeitos da declaração de inconstitucionalidade por não ter alcançado o número de votos exigido pelo art. 27 da Lei 9.868/99, e, consequentemente, a decisão aplica-se às eleições de 2016 e seguintes, a partir da Sessão de Julgamento, independentemente da publicação do acórdão. Com relação às pessoas físicas, as contribuições ficam reguladas pela lei em vigor." Disponível em: <http://redir.stf.jus.br/paginadorpub/paginador.jsp?docTP= TP\&docID=10329542>. Acesso em: 26 jun. 2017.
} 
contribuição, auxílio de recurso procedente de empresa privada, de finalidade lucrativa, entidade de classe ou sindical."

Com o processo de impeachment do presidente Fernando Collor de Mello, entretanto, eleito em 1989, tomou-se conhecimento de uma série de contribuições eleitorais clandestinas de empresas privadas, arrecadadas pelo tesoureiro de campanha, Paulo Cesar Farias. É assim a relação escusa entre o privado e o poder constituído, o que levou o Congresso a legislar pela necessidade de transparência e fiscalização das contas de campanha, permitindo, no entanto, em nome da transparência, a utilização de recursos empregados por empresas privadas. Backer (2014, p.3, online) anota:

\begin{abstract}
O tema estreou nos jornais, no período pós 1988 , por ocasião do impeachment do presidente Collor, quando veio à tona grande número de doações ilegais para a campanha do candidato. Contribuições de empresas eram na época proibidas, pela antiga LOPP (Lei Orgânica dos Partidos Políticos, Lei 5682/71, que vigorou entre 1971 e 1995). A reação legislativa foi liberar as doações de pessoas jurídicas a partidos e candidatos (Leis 9096/95 e 9504/97), definindo os parâmetros dentro dos quais essas doações poderiam ser feitas.
\end{abstract}

Desde então, inicialmente, com a nova Lei dos Partidos Políticos de nº 9096/95 e, posteriormente, a Lei das Eleições de $n^{\circ}$ 9504/97, passaram a se estabelecer as regras de financiamento dos partidos políticos e das campanhas eleitorais, possibilitando, assim a arrecadação e uso de valores e doações originárias de pessoa jurídica, dentro dos limites fixados. Note-se os artigos da Lei $n^{\circ}$ 9.504/97, que tratam deste tema, verbis:

Art. 24. É vedado a partido e candidato, receber direta ou indiretamente doação em dinheiro ou estimável em dinheiro, inclusive por meio de publicidade de qualquer espécie, de:

I - entidade ou governo estrangeiro;

II - órgão da administração pública direta ou indireta ou fundação mantida com recursos provenientes do Poder Público;

III - concessionário ou permissionário de serviço público;

IV - entidade de direito privado que receba, na condição de beneficiária, contribuição compulsória em virtude de disposição legal;

$\mathrm{V}$ - entidade de utilidade pública;

VI - entidade de classe ou sindical;

VII - pessoa jurídica sem fins lucrativos que receba recursos do exterior;

VIII - entidades beneficentes ou religiosas;

IX - entidades esportivas;

$\mathrm{X}$ - organizações não - governamentais que recebam recursos públicos;

XI - organizações da sociedade civil de interesse público.

Parágrafo único. Não se incluem nas vedações de que trata este artigo as cooperativas cujos cooperados não sejam concessionários ou permissionários de serviços públicos, 
desde que não estejam sendo beneficiadas com recursos públicos, observado o disposto no art. 81.

[...]

Art. 81. As doações e contribuições de pessoas jurídicas para campanhas eleitorais poderão ser feitas a partir do registro dos comitês financeiros dos partidos ou coligações.

$\S 1^{\circ}$ As doações e contribuições de que trata este artigo ficam limitadas a dois por cento do faturamento bruto do ano anterior à eleição.

verbis:

Depreende-se o que expresso nos artigos da Lei $n^{\circ}$ 9.096/95, que tratam deste tema,

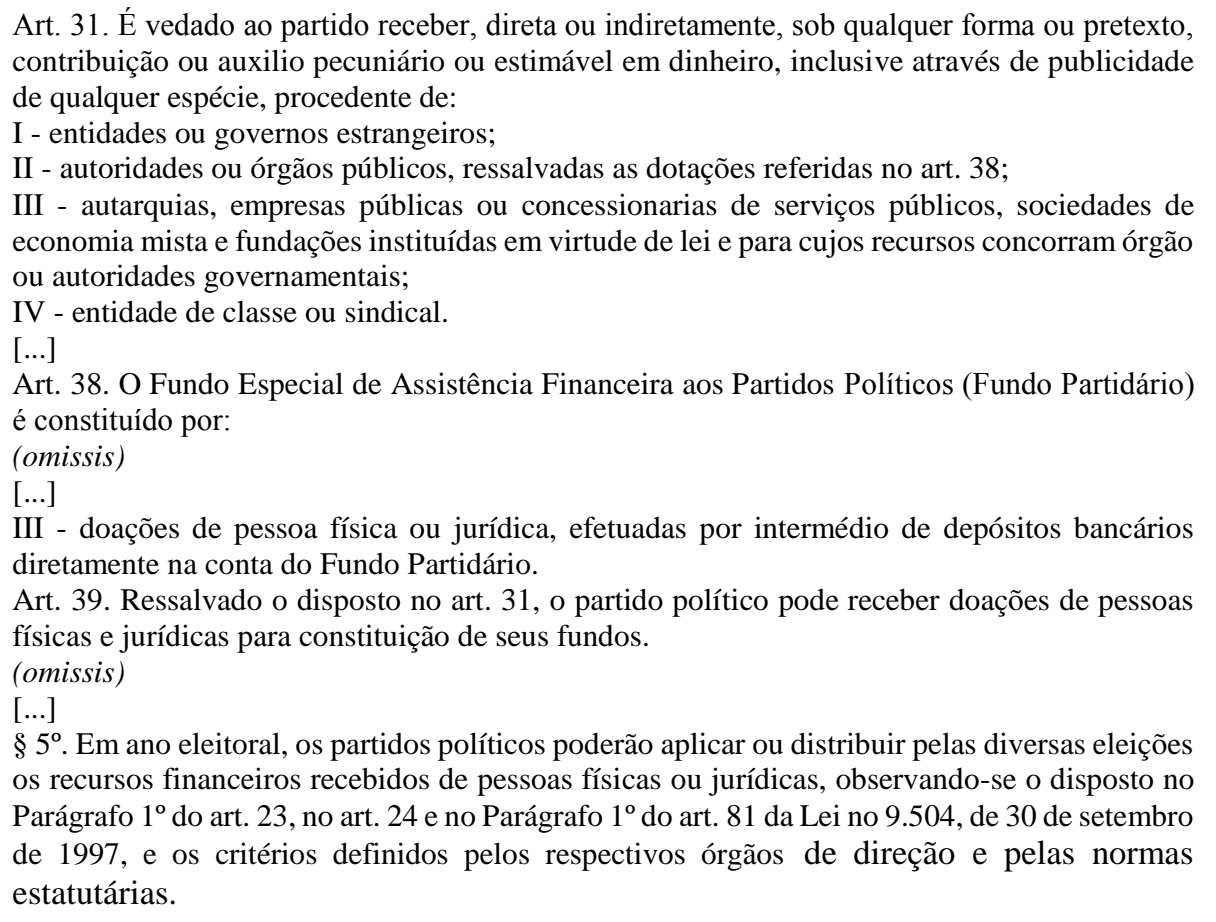

Essas regras, em linhas gerais, com pequenas alterações provocadas pelas Leis $n^{\circ} \mathrm{s}$ 12.034/2009 e 12.891/2013, fixaram a modalidade de financiamento de campanhas políticas no Brasil até às eleições gerais de 2014, e foram analisadas pelo Supremo Tribunal Federal na ADI 4650/DF.

Em resumo, os candidatos e partidos poderiam arrecadar de pessoas físicas, sempre no limite de $10 \%$ dos rendimentos recebidos no exercício anterior, e ainda de pessoa jurídicas, na estrema de $2 \%$ do faturamento, também, do exercício anterior, com a exceção das pessoas jurídicas impedidas, fixadas no $\S 1^{\circ}$ do art. 81 da Lei das Eleições. As pessoas físicas e jurídicas também poderiam contribuir para o fundo partidário, com as vedações constantes do art. 31 da Lei dos Partidos Políticos, com a possibilidade de proceder à distribuição desses valores no ano da eleição ( $\$ 5^{\circ}$ do art. 39 da 9.096/5). 
A realidade política brasileira começou a revelar uma relação promíscua entre empresas e Poder Público. Casos de grande repercussão nas medias - como "Mensalão", "Lava Jato" e, recentemente, o escândalo da JBS -comprovaram uma série de financiamentos ilegais a partidos políticos, políticos e candidatos. Significativos valores sem registro na prestação de contas e repasses de propinas decorrentes de superfaturamento de obras e serviços públicos foram repassados como doação de campanhas eleitorais.

Nesse comenos, o Supremo Tribunal Federal trouxe a julgamento Ação Direta de Inconstitucionalidade, proposta pela Ordem dos Advogados do Brasil, em 05 de setembro de 2011, que tomou o $\mathrm{n}^{\mathrm{o}}$ 4650/DF, na qual foi questionada a constitucionalidade dos artigos mencionados, para declarar, no âmbito de uma constituição principiológica, o financiamento político por pessoa jurídica, por incompatível com a Constituição Brasileira. (ADI No 4650/DF, 2011, online)

A mencionada Ação teve longa tramitação, tendo iniciado seu julgamento em 11 de dezembro de 2013, pelo voto do relator min. Luiz Fux, pela procedência da ação, o que foi acompanhado pelos ministros Joaquim Barbosa, Dias Toffoli e Luís Roberto Barroso, sendo suspensa com o pedido de vistas do min. Teori Zavascki.

Em 02 abril de 2014, o min. Teori Zavascki abriu a divergência do voto do ministro relator, votando pela improcedência da ação. Na mesma sessão, acompanharam o Relator, os ministros Marco Aurélio de Mello e Ricardo Levandowski, quando pediram vistas ao min. Gilmar Mendes, já havendo formado maioria.

Somente em setembro de 2015, o min. Gilmar Mendes trouxe os autos a julgamento, quando acompanhou a divergência, sendo seguido pelo ministro Celso de Melo. As ministras Carmem Lucia e Rosa Weber acompanharam a maioria formada. À época, o retardamento do longo período de vistas dos autos pelo min. Gilmar Mendes, quando já instalada a maioria pela proibição das doações de pessoas jurídicas, foi entendido como manobra processual, objetivando evitar os efeitos da decisão nas eleições de 2014(REDE BRASIL ATUAL, Gilmar Mendes trava decisão sobre doações privadas, que fica para o pós-eleições, 2014, online).

Concomitantemente à decisão já constituída no STF, o Congresso Nacional editou a Lei $\mathrm{n}^{\mathrm{o}}$. 13.165, de 29 de setembro de 2015, que alterou significativamente o modelo de financiamento de despesas eleitorais, estabelecendo, pela primeira vez, um limite de gastos para candidaturas, excluindo definitivamente o financiamento de candidatos e partidos políticos, por 
meio de pessoas jurídicas. Apesar da tentativa do Legislativo em manter o financiamento regular dos partidos políticos, com exceção de despesas de campanhas, essa exceção não vingou, em decorrência do veto da presidente Dilma Rousseff. (CÂMARA NOTÍCIAS, Mantido veto ao financiamento empresarial de campanhas eleitorais, 2015, online) . Gomes (2017, p. 429) relata o episódio:

\footnotetext{
No entanto, em 9/9/2015 foi aprovado na Câmara dos Deputados o Projeto de Lei no 5.735/2013 (que recebeu o ${ }^{\circ} 75 / 2015$ no Senado), o qual se transformou na Lei ${ }^{\circ}$ 13.165, de 29/9/2015. Esse projeto incluía na lei no 9.504/97 o artigo 24-B, que regulava as "doações e contribuições de pessoas jurídicas para campanhas eleitorais", as quais só poderiam ser feitas para partidos políticos - e não para candidatos. Ocorre que esse art. 24-B foi vetado pela Presidência da República, tendo o veto sido mantido no Congresso Nacional. No fundamento do veto, salientou-se que a "possibilidade de doenças e contribuições por pessoas jurídicas a partidos políticos e campanhas eleitorais [...] confrontaria a igualdade política e os princípios republicano e democrático, como decidiu o Supremo Tribunal Federal - STF em sede de Ação Direita de Inconstitucionalidade (ADI nº650/DF) [...]
}

As eleições municipais de 2016 já foram realizadas sob a vigência da nova lei, editada segundo a decisão proferida pelo Supremo Tribunal Federal, contando com financiamento privado apenas de pessoas físicas, além dos repasses originários do Fundo Partidário, horário eleitoral gratuito - bancado pelo estado à custa de isenção fiscal-, orçado, em 2016, no valor de 578 milhões.( O GLOBO, Horário Eleitoral 'custará' R\$ 576 milhões em 2016, 2016, online).

Como demonstrado, todo o arcabouço legislativo de financiamento privado de campanha foi limitado a pessoas físicas, excluindo por completo o financiamento de pessoas jurídicas, em face da decisão originária da ADI 4650/DF (STF -DJE, 2013, online).

\subsection{Fundamentos da decisão do STF na ADI 4650/DF}

A decisão do STF, formalizada em longo acórdão, trouxe à discussão uma série de pontos relevantes para serem abordados em análise científica, desde a abrangência do judicial review na Constituição Brasileira, o ativismo judicial e político do STF, a violação ao princípio da separação dos poderes, entre outros, que moldaram esse hard case. Este trabalho, entretanto, se limita à análise das razões de mérito expressas como fundamento da exclusão da possibilidade do financiamento político por pessoas jurídicas. Antecipa-se, contudo, a ideia de que, todos esses questionamentos preliminares foram suplantados no voto vencedor, do qual se 
destacam trechos de onde se subtrai o alargamento cada vez maior da competência do STF no campo das decisões políticas.

Frise-se, ademais, que essa opção por uma postura mais particularista do Supremo Tribunal Federal não tem que ver com uma suposta expertise para tratar com processo eleitoral. Na realidade, muitos membros da classe politica detém vasto conhecimento sobre a temática, além de conseguirem vislumbrar desenhos constitucionais muito efetivos em termos práticos. Contudo, o controle jurisdicional, aqui, decorre verdadeiramente da posição de maior insulamento de que desfruta o Poder Judiciário em face do poder politico quando comparado com o Legislativo e o Executivo.(STF -DJE, 2013, p. 40, online)

Ou ainda:

Diante disso, devem ser repudiadas visões idealizadas de democracia que desconsiderem a posição de interesse da instancia decisória. O deslinde de controvérsias de natureza politica não pode abster-se da analise de qual agente investido do maior grau de imparcialidade e neutralidade está apto para apreciar a matéria. Precisamente por isso, a objeção democrática, suscitada pela Presidência da Câmara dos Deputados e do Senado Federal, não desautoriza a intervenção judicial, visto que o exercício da jurisdição constitucional, na espécie, milita em favor do regime democrático. (STF-DJE, 2013, p. 41, online)

Os fundamentos de mérito que compõem o voto majoritário do STF não parecem ser menos questionáveis do que reconhecer o cabimento da propositura e da afirmação de competência da Corte Suprema, expresso na decisão. Passar-se-á, então, a delineá-las.

\subsubsection{Participação política de pessoas jurídicas incompatível em relação ao regime}

\section{democrático}

Em seu substantivo voto, o Relator assevera que "não me parece que seja inerente ao regime democrático, em geral, e à cidadania, em particular, a participação política por pessoas jurídicas". Pouco após, preceitua:

O exercício de direitos políticos é incompatível com a essência das pessoas jurídicas. Por certo, uma empresa pode defender bandeiras politicas, como a de direitos humanos, causas ambientais etc., mas daí a bradar pela sua indispensabilidade no campo político, investindo vultosas quantias em campanhas eleitorais, dista uma considerável distância.

A premissa imposta na fundamentação é de que a possibilidade de financiar campanhas eleitorais é própria do exercício dos direitos políticos, porquanto da cidadania, não extensivos 
às associações para fins empresariais, que são fictícias, na definição de Dworkin (STF -DJE, 2013, p. 49, online): “[...] as empresas são ficções legais. Elas não têm opiniões próprias para contribuir e direitos para participar com a mesma voz e voto na política”.

Tal premissa, no entanto, não é verdadeira, já que a mera participação política no financiamento de campanha não confere direitos políticos às associações empresariais, e sim direito de influenciar nas eleições. O exercício de capacidade eleitoral ativa e passiva é próprio da pessoa natural que, por sua vez, exercita opiniões e ideias, projetos e ideais, também por meio de suas pessoas jurídicas. Se uma sociedade comercial é uma ficção, então, ela não possui, pois, recursos próprios, porquanto, em última análise esses valores são de propriedade de seus sócios, e, sendo assim, quem estaria doando eram cidadãos em pleno exercício de seus direitos políticos.

Ocorre que as pessoas jurídicas, que são sempre constituídas por pessoais naturais, guardam legítimos interesses no desenvolvimento político de uma nação, nas políticas públicas a serem empregadas, na pauta econômica, educacional, de saúde, ecológica, enfim, em todas as áreas. $\mathrm{O}$ fato de não terem cidadania não lhes retira o direito de contribuir e participar politicamente para o bem-estar social, que possa, inclusive, influenciar nos seus legítimos lucros.

A visão das empresas, desde as microempresas até as grandes corporações, como incapazes de contribuir politicamente, parece desvencilhada da realidade do mundo liberal em que se vive. Ana Claudia Santano (2016, p. 80) comenta:

\begin{abstract}
A moderna noção de participação política extrapola o seu perfil jurídico de direito fundamental individual que se expressa por meio do voto e passa a ser percebido também na esfera coletiva, através da organização de cidadãos em grupos ou outras formas, motivados por interesses em comum, o que fortalece o alcance de suas demandas supera a debilidade da influencia individual de cada um deles. Escolher a maneira de como esta participação política será realizada também é o exercício deste direito, que não pode ser injustamente limitado a atuação individual e unitária.
\end{abstract}

Principalmente no Brasil, todo sistema tributário induz a pessoa natural a transformar sua atividade profissional em pessoa jurídica, independentemente da natureza da sua prestação de serviços, de sua atividade comercial ou industrial. A formalização da pessoa jurídica é incentivada pelo Estado brasileiro, como meio inclusivo de participação social. Por isso, criamse figuras, como microempresas, firmas individuais, sociedades individuais de responsabilidade limitadas, pequenas empresas, sociedades de advogados, e outros profissionais liberais, bem 
como inúmeras outras denominações que conduzem à formalização das atividades desenvolvidas por pessoas físicas. A tributação da pessoa física é substancialmente maior do que a imposta às jurídicas, o que, consequentemente, atrai a maior parte do capital e das riquezas para este segmento.

O dinheiro na política não pode ser demonizado, assim como, naturalmente, as pessoas jurídicas, por serem as maiores detentoras do capital. Não se faz política sem dinheiro. Os custos de uma campanha são altos, principalmente num país enorme como o Brasil. A cultura de comícios, longos deslocamentos de campanha, despesas com impressos, a confecção de programas em rádio e televisão, agora, em redes sociais, exigem significativos gastos. Não se pode simplesmente desconsiderar esta realidade. Quanto mais informado e envolvido esteja o eleitor, pressupõe-se um maior nível de participação política.

Quanto maior participação do cidadão, quer pessoalmente, quer por via de suas empresas, no financiamento de campanha, que detém legítimos interesses, pressupõe maior representação social no processo democrático, porquanto maior legitimidade dos representantes. Na verdade, o que se deve discriminar não é o dinheiro na política, mas o abuso de poder econômico.

O ministro Celso de Melo, em seu voto divergente na ADI 4650/DF (STF -DJE, 2013, p. 322, online), promove esta preocupação:

O que a Constituição da República não tolera nem admite é o abuso do poder econômico; não, porém, o seu regular exercício, cuja atuação não provoca os efeitos perversos - e deslegitimadores dos resultados eleitorais - que decorrem dos excessos que, efetivamente, devem ser coibidos.

O financiamento empresarial privado não pode ser eleito como o grande vilão do abuso do poder econômico na política, mesmo porque este abuso não deriva, obrigatoriamente, das pessoas jurídicas, mas pode ser realizado, inclusive, por pessoas físicas. Nada impede também que o abuso de poder econômico se instale, aliás como confirmado nos escândalos políticos, sem registro contábil, via caixas 2, 3 ou outras modalidades clandestinas. Ao contrário, medidas restritivas desta natureza estimulam as práticas irregulares, quando restringem as fontes legais de financiamento.

Não se defende aqui a liberação indistinta e ilimitada da utilização dos recursos originários de pessoas jurídicas, mas a possibilidade da doação com incentivo à participação 
política do cidadão e de suas empresas, pois que detém legítimos interesses políticos, cabendo ao Estado a fiscalização e o controle.

\title{
2.2.2 Plutocratização da política brasileira
}

O outro importante argumento para a vedação do financiamento de campanha política por empresas privadas se extrai, sumariamente, da seguinte afirmação do Relator:

\begin{abstract}
Não bastasse, outra consequência da adoção deste modelo é que o peso político atribuído à participação de uma pessoa jurídica variará de acordo com a sua renda. Quanto maior o poderio econômico da empresa doadora maior será a sua capacidade de influenciar decisivamente no resultado das eleições, o que induziria à indesejada "plutocratização" da política brasileira. (STF -DJE, 2013, online)
\end{abstract}

O exercício do poder, pela classe política mais abastada (plutocracia), não é decorrente da participação das pessoas jurídicas como financiadores de campanha, mas do critério legal censitário, previsto no então $\S 1^{\circ}$ do art. 81 da Lei das Eleições, que estabelecia o limite de doações, com base em $2 \%$ do faturamento de cada empresa no exercício anterior, tornando, logicamente, influentes as empresas com maior faturamento.

É que a Odebrecht terá maior peso na eleição do que o pequeno empreendedor do interior do Ceará, apesar de ambos terem legítimos interesses políticos a serem defendidos e afetados pelas políticas públicas governamentais.

Na medida em que há empresas que podem influenciar diferenciadamente na eleição, em decorrência do seu maior poder econômico, viola-se o princípio da igualdade, com reflexos danosos à representação democrática.

Cumpre destacar o fato de que esse modelo censitário não é exclusivo das doações atinentes às pessoas jurídicas, mas também próprio das doações de pessoas físicas, que não foram afetadas pela decisão do STF. Na conformação do art. $23, \S 1^{\circ}$ da Lei das Eleições, ${ }^{4}$ cada pessoa jurídica pode doar até $10 \%$ de seus rendimentos do exercício anterior a cada eleição. Igualmente às doações relativas às pessoas jurídicas, os individualmente mais ricos têm maior peso e importância no processo democrático.

\footnotetext{
${ }^{4}$ Art. 23. Pessoas físicas poderão fazer doações em dinheiro ou estimáveis em dinheiro para campanhas eleitorais, obedecido o disposto nesta Lei. (Redação dada pela Lei nº 12.034, de 2009)

$\S 1^{\circ}$ As doações e contribuições de que trata este artigo ficam limitadas a $10 \%$ (dez por cento) dos rendimentos brutos auferidos pelo doador no ano anterior à eleição.
} 
O princípio da igualdade e da paridade de votos deve ser respeitado. Cada cidadão deve ter o mesmo peso: uma pessoa, um voto. Quando há a violação dessa igualdade, tanto de pessoas físicas e jurídicas, também no financiamento e participação de campanhas, criam-se cidadãos e grupos associados com maiores direitos. Dispõe o art. 14 da Constituição Federal: “A soberania popular será exercida pelo sufrágio universal e pelo voto direto e secreto, com valor igual para todos, e, nos termos da lei, mediante".

A negação do princípio da igualdade advém não do financiamento de pessoas jurídicas, mas da criação de eleitores e financiadores diferenciados na medida do maior poder financeiro.

Mohallem (2015, p.101), alerta: “A Lei nesse ponto é marcada por inconstitucionalidade, já que ao estabelecer limite proporcional à renda, cria a nefasta distinção da participação no processo eleitoral baseada em capacidade econômica."

Assim, a formação de uma sociedade plutocrática não pode ser atribuída à participação das pessoas jurídicas no financiamento de campanha, mas à própria legislação que atribui peso diferenciado aos financiadores, segundo seu poder aquisitivo, criando um critério censitário de participação política.

\subsubsection{Liberdade de expressão de pessoas jurídicas}

Subtrai-se dos fundamentos gizados na decisão do STF, o questionamento da possibilidade de macular a liberdade de expressão das pessoas jurídicas, dentro do conflito aparente com os princípios republicano e democrático, supostamente atendidos na decisão. Assere o Relator:

\footnotetext{
Há, porém, um complicador no ponto: consiste em saber se há algum interesse constitucional contraposto que, a um só tempo, autorize a doação por pessoas jurídicas e justifique essa proteção insuficiente aos princípios democrático e republicano? Ou, como sustentam os defensores do modelo, o âmbito de proteção da liberdade de expressão abarca um direito fundamental das pessoas jurídicas realizarem doações em campanhas? Mais uma vez, a resposta é desenganadamente negativa. (STF -DJE, 2013, p. 31, online)
}

Prima facie, não se vislumbra, como, por si mesmo, a doação de pessoas jurídicas possa afetar os princípios da democracia e republicano. Ao contrário, todavia, estimula a participação política da sociedade organizada, efetivando maior transparência e detectados 
legítimos ou ilegítimos interesses. Idealizar um estado político sem a interferência privada organizada seria irreal. Ana Cláudia Santano (2016, p.80) salienta mais:

\begin{abstract}
O contexto democrático de hoje em dia atende a uma lógica mais ampla e considera as pessoas jurídicas como verdadeiros atores na esfera pública deliberativa, que sofrem os mesmos impactos de políticas públicas que o resto da sociedade e que estão de democraticamente legitimados a defender seus interesses e a participar na política pelo canal que mais lhes convenha. Por ser um direito muito vinculado à ideia de democracia, o que se deveria fazer eram ampliar a suas formas de realização, não restringi-las.
\end{abstract}

É esta visão inclusiva que se ousa defender - uma participação ampla, com a presença dos agentes sociais, quer individualmente, quer associados em grupos, mas de maneira igualitária. A sociedade anseia por uma experiência política mais vivenciada, que não se limite ao voto, mas que exponha os interesses - sejam econômicos, políticos ou financeiros - à mostra. A sociedade está cada vez mais distante de sua representação, e seus representantes mais ainda dos interesses da sociedade. É o que se chama hoje "“crise de representação" .

A exclusão da liberdade de expressão e manifestação dos interesses das associações empresariais, comunitárias e sindicais não atende ao direito fundamental da liberdade de expressão, em sua configuração ampla. Este direito à manifestação é objeto de reconhecimento, como no famoso caso Citizens United, na Suprema Corte dos Estados Unidos, mesmo que ainda não totalmente extensiva aos financiamentos de campanha, como Wowk (CONJUR, 2015, online), defendeu no artigo referendado.

Grosselli e Mezzaroba (CONPEDI-Belo Horizonte/MG, 2011, online) assinalam essa necessária participação social.

Verifica-se que o desenvolvimento de uma cultura de participação política para uma
cidadania plena depende da transformação das relações de poder, que tem produzido
concentração de renda, de informação e de saber. Da mesma forma, essa
transformação deve acontecer nas relações sociais, com o fortalecimento de
organizações sociais e comunitárias e com o surgimento de novos estilos de gestão
pública e de ação coletiva, possibilitando a inclusão da população nos processos
políticos decisórios.

Deve-se assegurar o concurso das pessoas jurídicas, de modo mais amplo quanto à sua participação no processo político, inclusive reconhecendo sua liberdade de expressão atinente à manifestação no rol dos doadores, no seu sentido mais abrangente, inclusivo e limitado, no seu aspecto quantitativo e igualitário, atendendo à garantia de um princípio republicano e democrático. 


\title{
2.2.4 Instrumentos de fiscalizações e de controle
}

Outro argumento, exposto pelo min. Luiz Fux como contraposição aos possíveis argumentos contrários, é que a problemática das doações de pessoas jurídicas não se limita à existência efetiva do controle e fiscalização estatal. Argumenta o voto:

\begin{abstract}
Outro ponto a ser analisado se refere aos mecanismos de controle dos financiamentos de campanhas. Nesse sentido, a Presidência da República afirma que a discussão em torno das doações por pessoas jurídicas deve girar em torno dos instrumentos de fiscalização e de controle. Também, neste pormenor, penso que tal argumento não tem o condão de afastar a inconstitucionalidade do modelo de doação por pessoas jurídicas. Isso porque defender com fortes tintas que a questão da doação por pessoas jurídicas se restringe aos mecanismos de controle e de transparência dos gastos, data máxima venia, me parece insuficiente para amainar o cenário de cooptação do poder político pelo econômico e resgatar a confiança da população no processo eleitoral. (STF-DJE, 2013, p. 31, online)
\end{abstract}

De fato, o aprimoramento da fiscalização e controle pelos meios estatais, na busca dos delitos, é função precípua e indelegável do Estado, devendo ser notoriamente perseguida, na medida do desvirtuamento de atividades lícitas. O ministro Celso de Melo, em voto vencido, asseverou:

\footnotetext{
Se houver infringência ao que dispõe a legislação eleitoral, a existência de controle severo, ao coibir o abuso, legitimará, então, respeitada a garantia do 'due process of law', a incidência das diversas sanções de direito eleitoral cominadas em nosso ordenamento positivo.

Bastante atuais, no exame da controvérsia ora em julgamento, as palavras com o que o então Presidente François Mitterrand encaminhou à Assembleia Nacional o projeto de lei que dispunha sobre a regulamentação, na República Francesa, do financiamento dos partidos políticos: '[...] Certamente, não imporemos a virtude, porque haverá sempre aqueles que burlarão a lei para cometer fraudes; no entanto, os desonestos serão dez vezes mais culpados e, por isso mesmo, deverão ser dez vezes mais penalizados [...].' (STF -DJE, 2013, online)
}

O que deve ser aprimorado ainda mais, e já se demonstrou competência para fazê-lo, como procedido em inúmeras investigações em andamento no Brasil, especialmente, no caso da "Lava Jato", é o aprimoramento do controle e fiscalização estatal. A simples vedação impõe a necessária conclusão de que o Estado não é capaz de realizar controle e nem fiscalização da ilegalidade. Importa o reconhecimento da ineficiência estatal. A ineficiência estatal será danosa 
em qualquer modelo de financiamento da política, seja público, privado, misto, por pessoas físicas ou jurídicas.

O min. Teori Zavascki exorta:

\begin{abstract}
Não nos iludamos, portanto, e insisto no ponto: o problema da abusiva interferência do poder econômico na política e nas campanhas eleitorais - que é uma realidade e que precisa ser combatida - não está no marco normativo, mas no seu sistemático descumprimento. Não é a norma, e sim o seu descumprimento, que propicia fenômenos sobejamente conhecidos da nossa história política, dos tipos eufemisticamente chamados, em tempos recentes, de 'recursos não contabilizados' (AP 470), mas que, em todo o tempo, se conhece popularmente como contribuições de 'caixa dois' e que, no passado, deu origem às malsinadas 'sobras de campanha' (CPI do governo Collor de Mello). (STF-DJE, 2013, p. 149, online)
\end{abstract}

A exegese é claramente reducionista, deslocando a raiz da ineficiência do sistema político às pessoas jurídicas, como grandes vilãs do abuso de poder econômico e corrupção existentes na sociedade brasileira. Eis a reflexão de Ana Claudia Santano (2016, p.79):

A moderna noção de participação política extrapola o seu perfil jurídico de direito fundamental individual que se expressa por meio do voto e passa a ser percebido também na esfera coletiva, através da organização de cidadãos em grupos ou outras formas, motivados por interesses em comum, o que fortalece o alcance de suas demandas supera a debilidade da influencia individual de cada um deles. Escolher a maneira de como esta participação política será realizada também é o exercício deste direito, que não pode ser injustamente limitado a atuação individual e unitária.

\title{
2.2.5 Violação ao princípio de isonomia entre pessoas jurídicas
}

Disse, por último, o ministro FUX:

Por fim, mas não menos importante, também vislumbro a inconstitucionalidade dos critérios de doação a campanhas por pessoas jurídicas sob o enfoque da isonomia entre pessoas jurídicas. E isso porque a Lei das Eleições, em seu art. 24, não estende tal faculdade a toda e qualquer espécie de pessoa jurídica. (STF-DJE, 2013, p. 32, online).

Fê-lo, o Ministro, com todo acerto. Havendo uma limitação, há valores razoáveis ${ }^{5}$ próprios a possibilitar maior participação social. Todas as pessoas jurídicas privadas poderiam doar legitimamente; ainda mais agora, quando os limites de gastos em campanhas foram

\footnotetext{
${ }^{5}$ Fala-se em R $\$ 20.000,00$ (vinte mil reais) como limite doação por pessoa jurídica.
} 
balizados pela reforma eleitoral nos arts. 18, $231^{\circ}$. -A e 24-C da Lei $n^{\circ} 13.165$, de 29/9/2015. É como dizem os tributaristas: seria expandir a base de arrecadação.

De fato, há inconstitucionalidade no interdito da participação de algumas pessoas jurídicas privadas, e outras não, como sindicatos e associações de classe, na possibilidade de exercendo sua liberdade de expressão política, contribuir financeiramente para as eleições, o que não justifica constitucionalmente o impedimento, por completo, da participação de pessoas jurídicas nas campanhas, como decidiu politicamente o STF, formulando novo sistema eleitoral de financiamento, em inegável protagonismo da reforma política.

\subsection{Das consequências da decisão do STF e a experiência das eleições de 2016}

As eleições municipais de 2016 já ocorreram sob a égide da proibição da participação de pessoas jurídicas privadas, segundo os novos paramentos previstos na Lei $\mathrm{n}^{\mathrm{o}} 13.165$, de 29/9/2015, como já dito, alterada em função do julgamento da ADI 4650/DF.

A seguir, reproduz-se uma pesquisa feita pelos quantitativos disponibilizados pelo TSE sobre os números dos candidatos eleitos a prefeito, em 2016, referente às cinco capitais com maior eleitorado e a participação das pessoas físicas no financiamento dessas campanhas.

\begin{tabular}{|l|c|c|c|c|c|}
\hline $\begin{array}{c}\text { Principais } \\
\text { Cidades }\end{array}$ & São Paulo & Fortaleza & Rio de Janeiro & Belo Horizonte & Salvador \\
\hline $\begin{array}{l}\text { Prefeitos } \\
\text { Eleitos }\end{array}$ & $\begin{array}{c}\text { João Dória } \\
\text { PSDB }\end{array}$ & $\begin{array}{c}\text { Roberto } \\
\text { Claudio - PDT }\end{array}$ & $\begin{array}{c}\text { Marcelo Crivela } \\
\text { PRB }\end{array}$ & $\begin{array}{c}\text { Alexandre Kalil } \\
\text { PHS }\end{array}$ & $\begin{array}{c}\text { ACM Neto } \\
\text { DEM }\end{array}$ \\
\hline
\end{tabular}

Rev. de Teorias da Democracia e Direitos Políticos | e-ISSN: 2525-9660 | Maranhão | v. 3 | n. 2 | p. 1 - 24 | Jul/Dez. 2017. 


\begin{tabular}{|l|c|c|c|c|c|}
\hline $\begin{array}{l}\text { Doação de } \\
\text { Pessoas Físicas }\end{array}$ & $64 \%$ & $84,92 \%$ & $2,730 \%$ & $24,87 \%$ & $29,95 \%$ \\
\hline $\begin{array}{l}\text { Número de } \\
\text { doadores }\end{array}$ & 311 & 121 & 71 & 62 & 253 \\
\hline $\begin{array}{l}\text { Doação de } \\
\text { Fundo } \\
\text { Partidário }\end{array}$ & $28,37 \%$ & $15,07 \%$ & $97,27 \%$ & $5,702 \%$ & $70,05 \%$ \\
\hline $\begin{array}{l}\text { Votos } \\
\text { Recebidos }\end{array}$ & 3.085 .187 & 678.847 & 1.700 .030 & 628.050 & 982.246 \\
\hline $\begin{array}{l}\% \text { Votos } \\
\text { recebidos. }\end{array}$ & $53,29 \%$ & $53,57 \%$ & $59,36 \%$ & $52,98 \%$ & $73,99 \%$ \\
\hline
\end{tabular}

* Os candidatos João Dória - PSDB/SP e Alexandre Kalil - PHS/MG, utilizaram recursos próprios, que representam $35,70 \%$ e $69,43 \%$, respectivamente, do total de recursos recebidos para a campanha.

Algumas constatações podem ser realizadas em razão das prestações de contas de campanha junto ao TSE, conforme ä frente expresso.

a) A primeira delas, e talvez a mais importante, é que o interdito da participação de pessoas jurídicas, seguramente, não estimulou ou induziu a uma maior participação das pessoas naturais no financiamento das campanhas. Dos dados disponibilizados pelo Tribunal Superior Eleitoral, concluiu-se que houve uma inexpressiva participação popular nas doações de campanha eleitoral. Os números mostram que a vedação do financiamento por pessoas privadas não estimulou e promoveu maior interação das pessoas físicas nas candidaturas. Por esse ângulo, pode-se concluir opostamente.

c) Houve cada vez maior participação do Fundo Partidário no financiamento das eleições, revelando uma tendência sempre crescente de financiamento público. Nesse cenário já se notícia nos principais veículos de imprensa (ESTADÃO, Sete partidos fazem acordo pela aprovação de fundo eleitoral de R \$ 3,5 bilhões, 2017, online), o aumento substancial para 3,5 bilhões do fundo partidário, protagonizado por algumas das maiores bancadas para eleições de 2018.

b) De maneira empírica, percebe-se um distanciamento dos valores gastos em campanhas anteriores, que talvez implique, não necessariamente uma redução dos valores 
gastos, mas somente uma formalização parcial $^{6}$, dentro dos lindes dos gastos estabelecidos pelo TSE, o que levaria a uma existência maior de valores não contabilizados, ou seja, a uma menor transparência.

A decisão do STF mais que do que moralizadora, se mostrou nociva à democracia e à participação cidadã no projeto político de seus representantes, excluindo legítimos agentes políticos, no caso, a pessoa jurídica, sob uma óptica reducionista e limitada da participação estatal no controle e fiscalização das ilegalidades.

\subsection{Hermenêutica Constitucional aplicada ao caso}

Na decisão do Supremo Tribunal Federal, em investigação, deu-se a declaração de inconstitucionalidade das regras infraconstitucionais previstas na Lei $n^{\circ}$. 9504/97 e $n^{\circ}$. 9096/95, especificamente as permissivas ao financiamento de partidos e campanhas políticas em face de conflito ou colisão com os princípios constitucionais da democracia, da igualdade e do pluralismo político.

Tal situação foi de logo posta no início do voto do Min. Relator:

A ação direta ora em análise suscita uma reflexão acerca dos limites e possibilidades da jurisdição constitucional em um Estado Democrático de Direito porquanto conclama que esta Suprema Corte se pronuncie acerca da validade jurídicoconstitucional das normas relativas ao financiamento de campanhas eleitorais - um dos pontos nucleares do nosso sistema político. (STF-DJE, 2013, p. 34, online).

Consoante afirmara o min. Luiz Fux, em artigo transcrito na nota 5, “A Constituição de 1988 não contém, em qualquer de suas disposições constitucionais, um tratamento específico e exaustivo no que concerne ao financiamento de campanhas eleitorais". Isso é verdade. A missão foi atribuída para o regramento infraconstitucional. Também se extrai que não há qualquer vedação explícita, quer em princípio ou regra decorrente da Constituição, que exclua o financiamento político por pessoas jurídicas.

Isso quer dizer que, segundo a hermenêutica produzida na decisão do STF, o fundamento da decisão deve considerar a prevalência dos princípios constitucionais invocados

\footnotetext{
${ }^{6}$ Quem acredita que a campanha de Dória a prefeitura de São Paulo custou apenas R\$ 12.330.127,76?
} 
sobre o regramento de financiamento definido pelo legislador ordinário, trazendo à tona o conflito entre princípios e regras.

Por não haver regras que vedem a permissão de financiamento político por pessoa jurídica privada, impossível seria invocar a antinomia entre regras, o que geraria aplicação do modelo "tudo ou nada" com a invalidação de uma. Dworkin (2002, p. 43) ensina: "Se duas regras entram em conflito, uma delas não pode ser válida. A decisão de saber qual delas é válida e qual deve ser abandonada ou reformulada, deve ser tomada recorrendo-se a considerações que estão além das próprias regras".

Assim, a decisão em investigação se arvorou de conflitar as normas de financiamento de campanha, com os princípios constitucionais que regem o sistema democrático brasileiro. Por ausência de antonímia entre os princípios elencados, com as regras "específicas" de participação das pessoas jurídicas privadas como financiadoras de campanha, e não com aquelas que permitem a desigualdade de financiamento entre os financiadores (pessoas jurídicas e físicas), se aplicou o que Streck denomina de pan-princiologismo:

\begin{abstract}
$\mathrm{Na}$ esteira da construção dessa busca pela determinação do conceito de princípio, surgiram, mormente nos anos mais recentes, situações inusitadas. Certamente, a mais pitoresca de todas é aquela que nomeada (em diversos textos e, especialmente, em: Verdade e Consenso, 2011b) de pan-principiologismo, uma espécie de patologia especialmente ligada às práticas jurídicas brasileiras e que leva ao uso desmedido de standards argumentativos que, no mais das vezes, são articulados para driblar aquilo que ficou regrado pela produção democrática do direito, no âmbito da legislação (constitucionalmente adequada). É como se ocorresse uma espécie de "hiperestesia" nos juristas, que os levasse a descobrir, por meio da sensibilidade (o senso de justiça, no mais das vezes, sempre é um álibi teórico da realização dos "valores" que subjazem o "Direito"), a melhor solução para os casos jurisdicionalizados.( Revista de Atualizações Legislativas, 2012 , p. 8-9)
\end{abstract}

Não havia, ao tempo da decisão, qualquer conflito entre regras e princípios, estritamente na parte declarada como inconstitucional, relativa à participação da pessoa jurídica privada como financiadora de campanhas, a exigir uma predominância dos princípios sobre as regras $^{7}$. De fato, malgrado a afirmação do ministro Fux, "que me parece indisputável que a Reforma Política deva ser capitaneada pela classe política, e não pelo Poder Judiciário” (STF -

\footnotetext{
${ }^{7}$ Com referência a estas regras, Mello ensina que: "violar um Princípio é muito mais grave que transgredir uma norma qualquer", porque conforme Streck, as normas constitucionais "são vinculativas e têm eficácia" e, portanto, ainda conforme Streck, desrespeitar uma norma constitucional significa "uma ruptura da própria Constituição". E isso, conforme Canotilho vale também para as normas programáticas, a qual "é reconhecido hoje um valor jurídico constitucionalmente idêntico ao dos restantes preceitos da constituição". KOHN, Edgar. A Solucao da colisao de principios e conflito de regras. Boletim Jurídico, Uberaba/MG, ano 12, n.752, 2010. Disponível em: <http://www.boletimjuridico.com.br/doutrina/texto.asp?id=2182>. Acesso em: 25 jun. 2017.
} 
DJE, 2013, p. 38, online), é exatamente o que promove com a decisão que veda a doação por pessoas jurídicas privadas; E não o faz desatento ao princípio da separação dos poderes, eis que, ao indagar, responde:

É factível confiar única e exclusivamente aos agentes políticos a prerrogativa de reformulação das regras concernentes ao financiamento de campanhas, quando, em verdade, foi o exato sistema em vigor que permitiu a sua ascensão aos cargos que ocupam? A resposta é, a meu juízo, negativa. (STF-DJE, 2013, p. 38, online)

Assim, a reforma política, a começar pela relativa ao financiamento da política, tem ingerência e protagonismo pelo STF, que, se considerando com maior expertise, numa visão solipsista, assume esse caráter reformador, sob a desculpa de aferir a "validade jurídicoconstitucional das normas relativas ao financiamento de campanhas eleitorais", modificando o que restou democraticamente decidido ou somente pela via legislativa deva ser exercitada, sob um senso de justiça próprio.

O Ministro Teori Zavascki sintetizou bem em seu voto:

É evidente, repita-se, que o marco normativo deve ser aperfeiçoado, mas não será a destruição do modelo existente, com o consequente restabelecimento de modelo anterior, que levará a esse aperfeiçoamento. A experiência comparada demonstra, no que toca às fontes de financiamento de partidos e campanhas, que o sensível e complexo empreendimento normativo está inserido necessariamente em contexto mais amplo e mais profundo de reforma política, especialmente do sistema eleitoral, empreendimento que, por elementar imposição do sistema constitucional de democracia representativa, é do Poder Legislativo. (STF-DJE, 2013, p. 156, online)

\section{CONCLUSÃO}

A inércia do Legislativo em tratar da reforma política no Brasil, inclusive com modelo mais participativo da sociedade organizada, provoca uma atitude cada vez mais ativa politicamente e substitutiva do Parlamento pelo Supremo Tribunal Federal, que interpreta elasticamente os princípios constitucionais, e promove exatamente o que nega fazer, ou seja, o início de uma reforma política.

Mediante a análise do julgamento da ADI 4650/DF, especialmente do voto vencedor do min. Luiz FUX, se extrai a inexistência de qualquer princípio constitucional que possa 
conflitar diretamente com as regras infraconstitucionais que possibilitam a doação a campanhas políticas por parte de pessoas jurídicas privadas.

As inconstitucionalidades decorrem sempre da atribuição de um modelo há muito existente, e que ainda permanece, mesmo com a decisão do STF, de participação censitária aos doadores privados, hoje pessoas físicas, anteriormente, físicas e jurídicas, na medida que podem doar, de acordo com sua capacidade econômica.

A solução deve vir das forças democráticas, mediante legítima pressão social, que possibilite, de modo inclusivo, a existência de pessoas jurídicas, vez que estas detêm inegável interesse político no exercício de sua liberdade de expressão, e não decorrente de um senso jurídico comum implantado pelo Judiciário, denominado pan-princiopologia.

O valor das doações deve ser igualitário, independentemente da condição econômica da pessoa física ou jurídica, em limite razoavelmente baixo, a fim de aumentar a base de arrecadação e envolver o maior número de pessoas e a sociedade organizada, atendendo ao princípio da igualdade e da paridade, cabendo ao Estado o controle e a fiscalização efetiva da aplicação.

A democracia exige custos, respeito à separação dos Poderes, maior inclusão das forças sociais e da sociedade, que traga ao cidadão o direito de escolha de seus representantes, segundo suas propostas. Isso é difícil? Não. É quase impossível. Aí resta ao cidadão perseguir o ideal, reproduzindo a célebre frase de Winston Churchill, no início citada: "A democracia é a pior forma de governo, salvo todas as demais formas que têm sido experimentadas de tempos em tempos."

\section{REFERENCIAS}

BACKER, Ana Luiza. Financiamento das Campanhas Eleitorais. Brasília: Câmara dos Deputados, 2014. Disponível em: <http://www2.camara.leg.br/a-camara/documentos-epesquisa/fiquePorDentro/temas/financiamento-de-campanha/TextobasedaConsultoria.pdf $>$. Acessado em: 26 jun. 2017.

BRASIL. Lei $\mathrm{n}^{\circ}$ 9.096, de 19 de setembro de 1995. Dispõe sobre partidos políticos, regulamenta os arts. 17 e 14, § $3^{\circ}$, inciso V, da Constituição Federal. Diário Oficial da União, Brasília, DF, 20 de setembro de 1995. Disponível em: <http://www.planalto.gov.br/ ccivil_03/ leis/L9096.htm>. Acesso em: 26 jun. 2017. 
BRASIL. Lei n ${ }^{\circ}$ 9.504, de 30 de setembro de 1997. Estabelece normas para as eleições. Diário Oficial da União, Brasília, DF, de $1^{\circ}$ de outubro de 1997. Disponível em: <http:// www.planalto.gov.br/ccivil_03/leis/_L9504.htm>. Acesso em: 26 jun. 2017.

BRASIL. Supremo Tribunal Federal. Ação Direta de Inconstitucionalidade no 4650 DF. Relator: Min. LUIZ FUX, Data de Julgamento: 30/10/2013, Data de Publicação: Diário de Justiça Eletrônico, DIVULG 05/11/2013 PUBLIC 06/11/2013. Disponível em: <https://stf. jusbrasil.com.br/jurisprudencia/24611823/acao-direta-de-inconstitucionalidade-adi-4650-dfstf>. Acesso em: 26 jun. 2017.

CHURCHILL, Winston. Em discurso na Casa dos Comuns, em 11 de novembro, 1947. Disponível em: <https://richardlangworth.com/worst-form-of-government>. Acesso em: 26 jun. 2017.

DWORKIN, Ronald. Levando os direitos a sério. 3. ed. Tradução Nelson Boeira. São Paulo: Martins Fontes, 2002.

FUX, Luiz. Voto. Notícias STF. Disponível em: <http://www.stf.jus.br/arquivo/cms/ noticiaNoticiaStf/anexo/ ADI4650relator.pdf>. Acesso em: 23 jun. 2017.

FUX, Luiz; FRAZÃO, Carlos Eduardo. Novos Paradigmas do Direito Eleitoral. Belo Horizonte: Fórum, 2016.

GILMAR Mendes trava decisão sobre doações privadas, que fica para o pós-eleições. Rede Brasil Atual. 2014. Disponível em: <http://www.redebrasilatual.com.br/eleicoes-2014/ possibilidade-de-stf-decidir-sobre-financiamento-de-campanha-agora-e-remota-1861.html $>$. Acesso em: 26 jun. 2017.

GOMES, José Jairo. Direito Eleitoral. 13. ed. São Paulo: Atlas, 2017.

HORÁRIO Eleitoral 'custará' R \$ 576 milhões em 2016. O Globo. 2016. Disponível em: $<$ http://blogs.o globo.globo.com/blog-do-moreno/post/horario-eleitoral-custara-r-576milhoes-em-2016.html>. Acesso em: 26 jun. 2017.

KOHN, Edgar. A Solucao da colisao de principios e conflito de regras. Boletim Jurídico, Uberaba/MG, ano 12, n.752, 2010. Disponível em: <http://www.boletimjuridico.com.br/ doutrina/texto.asp?id=2182>. Acesso em: 25 jun. 2017.

LINDNER, Julia; BONFIM, Isabela; FARIA, Thiago. Sete partidos fazem acordo pela aprovação de fundo eleitoral de R \$ 3,5 bilhões. Estadão. Disponível em: <http://politica. estadao.com.br/noticias/geral,sete-partidos-fazem-acordo-pela-aprovacao-de-fundo-eleitoralde-r-3-5-bilhoes, 70001854823>. Acesso em: 23 jun. 2017.

MANTIDO veto ao financiamento empresarial de campanhas eleitorais. Câmara Notícias. Disponível em: <http://www2.camara.leg.br/camaranoticias/noticias/POLITICA/500324- 
MANTIDO-VETO-AO-FINANCIAM ENTO-EMPRESARIAL-DE-CAMPANHASELEITORAIS.html>. Acesso em: 26 jun. 2017.

MIGUEL, Luís Felipe. Democracia e Representação: Territórios em disputa. São Paulo: Unesp, 2014.

MINISTRO Herman Benjamin vota pela cassação da chapa Dilma-Temer por abuso de poder político e econômico. TSE Notícias. Disponível em: <http://www.tse.jus.br/imprensa/ noticias-tse/2017/Junho/ministro-herman-benjamin-vota-pela-cassacao-da-chapa-dilmatemer-por-abuso-de-poder-politico-e-economico>. Acesso em: 26 jun. 2017.

MOHALLEM, Michael Freitas. Doação ou investimento? Alternativas ao financiamento desigual de campanhas eleitorais. FALCÃO, Joaquim (org). In: Reforma eleitoral no Brasil: Legislação, democracia e internet em debate. (Org.) Joaquim Falcão. Rio de Janeiro: Civilização Brasileira, 2015.

ORDEM DOS ADVOGADOS DO BRASIL - OAB. Ação Direta de Inconstitucionalidade. Disponível em: <http://www.oab.org.br/arquivos/4650-1977686879-1794267.pdf>. Acesso em: 26 jun. 2017.

SANTANO, Ana Cláudia. O Financiamento da Política: Teoria Geral e experiências no direito comparado. 2. ed. Curitiba: Íthala, 2016.

STRECK, Lênio Luiz. Do pan-principiologismo à concepção hipossuficiente de princípio: Dilemas da crise do direito. Revista de Atualizações Legislativas, Senado Federal, Brasília, ano 49, n.194, p.8-9, abr./jun. 2012.

ZAVASCKI, Teori. Voto. Notícias STF. Disponível em: <http://www.stf.jus.br/arquivo/cms/ noticianoticia stf/anexo/adi4650tz.pdf >. Acesso em: 23 jun. 2017.

WOWK, Rafael. Discussão sobre financiamento eleitoral no STF difere da Citizen United nos EUA. Conjur: 2015. Disponível em:<http://www.conjur.com.br/2015-set17/rafael-wowk-discussao-stf-difere-citizen-united-eua>. Acesso em: 23jun. 2017. 